\title{
Gestão Intercultural: Percepção de Gestores da Agroindústria do Sudoeste Paranaense
}

\author{
Intercultural Management: \\ Perception of Agroindustrial Managers \\ in the Southwest of Paraná
}

\author{
BEATRIZ LEITE GUSTMANN DE CASTRO D \\ GIOVANNA PEZARICO D \\ MARIA DE LOURDES BERNARTT (iD
}

VÂNIA MEDIANEIRA FLORES COSTA (D)

\section{RESUMO}

Este trabalho busca analisar a percepção de gestores em relação à gestão intercultural em organizações no setor da agroindústria na região Sudoeste do Estado do Paraná. Tal problematização centra-se na escassez de estudos em relação a gestão intercultural, especialmente ao se tratar da inserção de trabalhadores oriundos de outros países. A região Sudoeste do Estado do Paraná, foi palco de destino de trabalhadores haitianos que foram admitidos nas agroindústrias da região. Para tanto, realizou-se uma pesquisa descritiva, de caráter qualitativo, por meio da técnica de análise de conteúdo. Dessa análise emergiram, três categorias: reconhecimento do outro, diferença e identidade. Os resultados evidenciaram a ineficácia da comunicação, uma vez que, os trabalhadores migrantes não dominam a língua portuguesa, interferindo na interação com o ambiente de trabalho. Todavia, a gestão intercultural proporciona aprendizagens significativas relativo à diversidade, o reconhecimento do outro, assim como a interação entre culturas.

Palavras-Chave: Gestão Intercultural. Cultura. Ambiente de Trabalho. 


\section{Abstract}

This paper seeks to analyze the perception of managers in relation to intercultural management in organizations in the agribusiness sector in the Southwest region of the State of Paraná. Such problematization focuses on the scarcity of studies in relation to intercultural management, especially when it comes to the insertion of workers from other countries. The Southwest region of the State of Paraná, was the destination stage for Haitian workers who were admitted to the region's agro-industries. For this, a descriptive, qualitative research was carried out, using the technique of content analysis. From this analysis, three categories emerged: recognition of the other, difference and identity. The results showed the inefficiency of communication, since migrant workers do not speak Portuguese, interfering in the interaction with the work environment. However, intercultural management provides significant learning related to diversity, the recognition of the other, as well as the interaction between cultures.

Key-words: Intercultural Management. Culture. Desktop.

\section{INTRODUÇÃo}

A aproximação de pessoas e territórios tem sido possível em função da globalização que proporciona a interação entre culturas distintas, apresentando impressões culturais, símbolos, formação de opiniões e estereótipos em relação a essas culturas. A mobilidade é marcada pelo convívio de pessoas de diversas nacionalidades imbuídas de diferenças culturais dentro do mesmo ambiente organizacional. Assim, tais diferenças culturais precisam ser consideradas, para amenizar e/ou evitar as dificuldades de gestão e relacionamentos entre os indivíduos (CRAIDE, 2011, 2012).

O produto das interações interculturais pode ser tão diverso quanto a multiplicidade de referências culturais, as quais, segundo Geertz (1989), refletem uma condição intrínseca ao ser humano que é o vínculo a uma teia de significados simbólicos, os quais, ao longo da vivência humana, são construídos, reconstruídos e aprendidos por grupos sociais ao se sucederem as gerações. Segundo Canclini (2003), um dos possíveis efeitos dessa aproximação cultural é a necessidade de se aprofundar temas associados a interculturalidade nas organizações, ao se considerar que nesses ambientes o foco 
não se resume apenas às transações negociais, mas a aprendizagem decorrente da síntese dessas vivências.

No entendimento de Freitas (2009), embora a miscigenação de culturas não configure um fenômeno recente, é a possibilidade da movimentação de pessoas e organizações que origina um espaço heterogêneo de trabalho e exige o desenvolvimento de novas aptidões e habilidades na convivência intercultural. A partir das relações que são estabelecidas entre diferentes culturas, singularmente no ambiente de trabalho, faz-se necessário refletir mais profundamente acerca de temas ligados a interculturalidade, pois, de acordo com, Gondim \& Fischer (2009, p. 10), “a gestão intercultural, significa o exercício de função de liderança com o objetivo de gerir negócios, processos e pessoas em contextos de diversidade cultural".

$\mathrm{O}$ encontro intercultural denota a relevância de se refletir de maneira exaustiva, sobre temas relacionados a gestão intercultural no campo das organizações, bem como as interações que se delineiam entre sujeitos de culturas diferentes. Entre as vantagens das equipes interculturais estão a variedade de perspectivas, habilidades, abordagens mais criativas, identificando melhor um problema e gerando melhores soluções (RODRIGUES, 2012; HAJRO, GIBSON, PUDELKO, 2015).

Considerando a interculturalidade como uma realidade no âmbito organizacional que demanda atenção, assim como, o desenvolvimento de novas aptidões e habilidades na convivência intercultural de gestores, uma vez que, essa nova realidade é enfrentada, é preciso habilitar profissionais para o encontro e o convívio com as diferenças culturais, de modo que, possam compreendê-las e, alguns casos, a aceitá-las. Frente ao exposto, a elaboração deste estudo justifica-se, tendo em vista, que a presença de times culturais ratifica a importância de se compreender como gerenciar equipes culturalmente distintas agregando valor e eficiência a tais interações, gerando produtividade, criatividade e inovação (BANISKI, CIESLAK, 2018).

Diante das exposições feitas objetiva-se, neste artigo, analisar a percepção de gestores em relação à gestão intercultural em organizações do setor da agroindústria situadas na região Sudoeste do Estado do Paraná. A realização deste estudo, justifica-se pela carência de abordagem de estudos vinculados a temática da interculturali- 
dade, especificamente, da inserção de trabalhadores migrantes de nível operacional, visto que, as ênfases das pesquisas existentes centram-se na expatriação de executivos.

O estudo torna-se relevante pelo fato de que, se materializa ao apresentar elementos teóricos e empíricos de uma temática com poucos diálogos nas agendas de pesquisas brasileiras. $\mathrm{O}$ artigo apresenta uma análise da gestão intercultural, inserindo a percepção de gestores que vivenciam práticas de gestão, voltada a equipes interculturais que integram trabalhadores haitianos no ambiente laboral.

Com base no exposto, este artigo está estruturado em cinco seções, incluindo a introdução. A segunda seção apresenta a base teórica sobre cultura, gestão intercultural e suas dimensões. $\mathrm{Na}$ terceira seção, aborda-se o método da pesquisa utilizado para operacionalização do estudo. Na quarta seção, apresenta-se os resultados e as discussões, e, por fim, na seção cinco são detalhadas as considerações finais, limitações e sugestões para pesquisas futuras.

\section{FUNDAMENTAÇÃo TEÓRICA}

No intuito de embasar teoricamente a proposta desse estudo, a presente seção subdivide-se nos seguintes tópicos: Diversidade e Cultura Organizacional e Gestão Intercultural nas Organizações.

\subsection{Diversidade e Cultura Organizacional}

No Brasil, segundo Mendes (2005) a produção acadêmica sobre a diversidade teve início a partir do ano 2000. As pesquisas realizadas ao longo dos anos sobre diversidade não possuem uma convergência conceitual, contudo neste estudo toma-se por base o conceito cunhado por Thomas Jr. (2003) em que considera a diversidade como diferenças e semelhanças que aproximam as pessoas, não focando somente a diferença, pois amplia a concepção de diversidade ao destacar, as semelhanças como fator presente nas interações humanas, direcionando para o sentido cultural.

A temática da diversidade tem se consolidado na pauta empresarial em contexto mundial, principalmente em razão das diferenças na força de trabalho. Aspectos como gênero, etnia, orientação sexual, idade, crença religiosa ou limitações físicas, por exemplo, 
assinalam a heterogeneidade (NKOMO, COX, 1994; FLEURY, 2000; ALVES, GALEÃO-SILVA, 2004). Galvin (2006) sinaliza que a partir da década de 1980, a diversidade emergiu como um dos mais profícuos temas em estudos organizacionais sob a perspectiva de que a inclusão melhoraria o ambiente de trabalho, alterando-o para mais diversificado e democrático.

A diversidade descrita por Freitas (2000, 2009) pode significar não apenas uma composição numérica que reflete diferentes tipos de pessoas, como origens étnicas, experiências profissionais e formação acadêmica. Para essa autora, significa diferentes atitudes, valores, ideias, perspectivas e experiências. No entanto, configura-se como desafio a construção de condições favoráveis à expressão desta diversidade de forma colaborativa e complementar, sem negligenciar as necessidades psicológicas e emocionais que fazem parte de todo ser humano e as suas múltiplas formas de expressão. Em outras palavras, a ideia da autora é fazer com que o trabalhador migrante se sinta parte do ambiente corporativo, em que tenha espaço para expressar suas opiniões, ser valorizado como o trabalhador nacional.

É válido considerar que as interações entre as diferentes identidades individuais podem contribuir para a formação da cultura organizacional, uma vez que "[...] as diferenças de identidade (tanto física, quanto culturais) interagem em uma complexa gama de fatores individuais, grupais e organizacionais (cultura de diversidade) para determinar o impacto da diversidade nos resultados individuais e organizacionais" (COX Jr., 1994, p. 335). Para Aranha (2018), as empresas bem-sucedidas adotam algumas iniciativas de diversidade como (i) uma fonte de vantagem competitiva; (ii) uma forma de justiça social e responsabilidade corporativa; (iii) necessidade regulatório ou legal; bem como, (iv) algo elementar para a estratégia de crescimento corporativo.

Considerando o espaço temporal, verifica-se a partir da exposição de Cox Jr. (1994) e Aranha (2018), que a diversidade agrega valores na organização em termos de resultados e de pluralidade no ambiente laboral, mas alguns estudos constataram que a diversidade apenas é uma falácia nas políticas organizacionais. Irigaray \& Saraiva (2009) observaram em um estudo empírico contradições entre o discurso e práticas adotadas, atribuindo a causa ao preconceito (não 
latente ou inconsciente) dos próprios trabalhadores da organização, a uma certa condescendência no nível gerencial e ao desenvolvimento de políticas que atentem antes com o mercado do que com as necessidades sociais. Por outro lado, Aranha (2018) explica que as políticas de diversidade nas organizações são retóricas, ou ainda discursos vazios e se ocorrem de fato, algum tipo de engajamento que acaba por trazer benefícios não somente para o espaço laboral em questão, mas também para a sociedade (ARANHA, 2018).

A diversidade especialmente, a cultural refere-se às particularidades humanas, as quais tornam os indivíduos diferentes uns dos outros, sendo considerada, um desafio complexo às organizações. Assim, é necessário compreender que a diversidade atrelada a cultura da organização, possibilita a condução das diferenças contextuais seja realizada de maneira cuidadosa, e utilizando-a como alavanca para vantagens competitivas, reduzindo possíveis impactos negativos que possam surgir a partir dessa heterogeneidade (PEREIRA, HANASHIRO, 2010).

Deste modo, aprofundar os estudos em organizações denotam lócus privilegiado do processo civilizador da inserção de trabalhadores oriundos de outras culturas. A partir da diversidade, é que se observa a relevância das pessoas para o cenário organizacional, tal como a cultura que se delineia no cotidiano do ambiente corporativo. A cultura individual é influenciada por diversos aspectos. Cada trabalhador trouxe consigo suas tradições, hábitos, costumes, gerando diversidade de culturas, que impacta na cultura do ambiente organizacional (RAMBO, DIEHL, 2015).

Por sua vez, no campo dos estudos organizacionais, Schein (1992) já estabelecia que o conceito de cultura organizacional parte de uma abordagem social-antropológica focada na noção de cultura como conjunto de princípios compartilhados que regem grupos que compõem organizações. Culturas diferenciam e caracterizam o modus operandi dessas organizações enquanto coletividades formalmente estruturadas. Ainda, a cultura refere-se ao conjunto de crenças, princípios e valores compartilhados pelos membros de uma mesma sociedade, neste caso, de um mesmo espaço laboral (HOUSE, et al., 2004). 
No contexto das organizações que possuem trabalhadores oriundos de outras culturas, emerge a diversidade cultural. Para tanto, a gestão da diversidade tem como eixo norteador os princípios, valores, condutas que são adotadas no ambiente corporativo. Autores como Lloyd (2002); Schuerkens (2004) e Canclini (2005) afirmam que muitos dos elementos culturais que os indivíduos trazem consigo são modificados durante a integração nos novos ambientes locais, sendo reinterpretados em função da realidade cultural local, transformando-se em algo único e novo.

Os estudos desenvolvidos sobre a cultura no ambiente corporativo, de modo geral, tratam sobre o conjunto de valores e princípios que orientam as práticas organizacionais, além de, normas e condutas. Nessa lógica, o estudo em questão procura ressaltar que, a constituição da organização dotada de símbolos, além da cultura formada e disseminada por seus fundadores, sócios e/ou gestores, convive culturas distintas, fruto de histórias de vida, valores, princípios, referências, formações culturais diversas de seus membros (RODRIGUES, 2012).

Assim, os fluxos culturais advindos da diversidade ocorrem a partir da convergência e homogeneização no novo ambiente, neste sentido, reforça-se o papel da cultura, que estabelece formas de condutas e valores para os sujeitos envolvidos. Dessa forma, tanto as políticas quanto a cultura funcionam como um "pano de fundo" que orienta os procedimentos de trabalho, principalmente as atividades de caráter mais técnico, e os comportamentos esperados em determinadas situações. Com isso, diminui-se a tensão e o desconforto inicial - de ambas as partes, estrangeiros e organizações - e menos estranhezas no que concerne ao desempenho das atividades profissionais (BUENO, FREITAS, 2018). A partir do momento em que culturas diferentes entram em contato, faz-se presente a interculturalidade, passe-se a seguir a discorrer no próximo tópico.

\subsection{Gestão Intercultural nas Organizações}

De acordo com Freitas (2000) as pesquisas interculturais no que diz respeito as formas de gestão passaram a ser divulgadas no final da década de 1980. Contudo, na maioria das vezes, têm se amparado em temáticas relativo a expatriações e expatriados, 
coordenação de equipes multiculturais, processos migratórios, bem como em estratégias de fusão e aquisição considerando as diferentes culturas, sobressaindo as pesquisas de natureza empírica, as quais centram-se em estudos comparativos entre culturas nacionais. A autora acrescenta que é na Europa, que os estudos têm se intensificado, devido as pessoas estarem habituadas a cruzar fronteiras geográficas e linguísticas, principalmente a partir da unificação dos países na Comunidade Europeia.

Em referência às pesquisas brasileiras, a análise sobre a interculturalidade ocorre, normalmente, quando os autores visam a identificar como se estabelece a relação entre nativos e estrangeiros; quais as peculiaridades constatadas pelos pesquisadores acerca das diferentes culturas; quais são as reações frente às diferenças e às semelhanças do "outro". Além disso, no Brasil, os estudos são incipientes nesta área, e ainda há pouco interesse no tema, fato que pode ser conferido, segundo Freitas (2009), nas dimensões continentais do país, à inexistência de cobrança de reparações históricas relativo aos colonizadores do Brasil e a um suposto consenso relativo a existência de uma cultura e um povo que incorpora várias etnias e culturas.

Para tanto, a literatura acadêmica assinala que a gestão de grupos de pessoas com culturas nacionais diferentes é uma realidade para um número cada vez maior de organizações. Chevrier (2000) argumenta que, para gerenciar pessoas com culturas diferentes, é preciso primeiro reconhecer a própria cultura. E o contato com o outro favorece esse reconhecimento. Contudo, a formação de equipe interculturais é mais do que o reconhecimento das diferenças entre seus membros. Neste sentido, Matveev e Nelson (2004) frisam que, a gestão da interculturalidade e dos conflitos entre culturas incitam adversidades acerca de desenvolver e manter coesão da equipe, gerenciar as diferenças e conflitos, manter a comunicação coerente, lidar com os significados culturais de cada membro.

A gestão intercultural parte do pressuposto que é imprescindível dispor de habilidades para considerar a identidade, diferença cultural e reconhecimento do outro que estão imbricados no processo de gestão intercultural. Temporariamente, o contato com o novo provoca uma quebra, uma ruptura, sendo considerado normal, saudável e humano que uma pessoa desenvolva mecanismos de defesa 
quando ela está ameaçada, e defenda a sua identidade e cultura em xeque, agarrando-se aos seus pontos de referências que lhes dão sustentação. É salutar, que uma pessoa saiba reconhecer-se culturalmente e é tão importante não depreciar a cultura, a identidade, o reconhecimento do outro. Para tanto, há quem rejeita completamente qualquer coisa que venha do outro; que, mascarando ou não, invalida qualquer aproximação, qualquer interação, qualquer contato (FREITAS, 2000, 2009; MATVEV; NELSON, 2004; BUENO; FREITAS, 2009; HAJRO; GIBSON, PUDELKO, 2015; BUENO, FREITAS, 2018).

No intuito de compreender as peculiaridades da gestão intercultural, acrescenta-se as observações de Friedman e Antal (2005), acerca dos problemas emergentes da gestão, sinalizam que, não raro, a literatura que aborda o tema no âmbito das organizações entende as diferenças interculturais como problemas de conflitos. Valendo-se da metáfora de um iceberg (Figura 1), os autores discorrem que, membros de diferentes culturas mantêm-se atrelados a uma base de valores e premissas de tal forma que raramente conseguem visualizar algo abaixo da "marca d'água", mantendo-se na superfície do que seria seu patrimônio cultural.

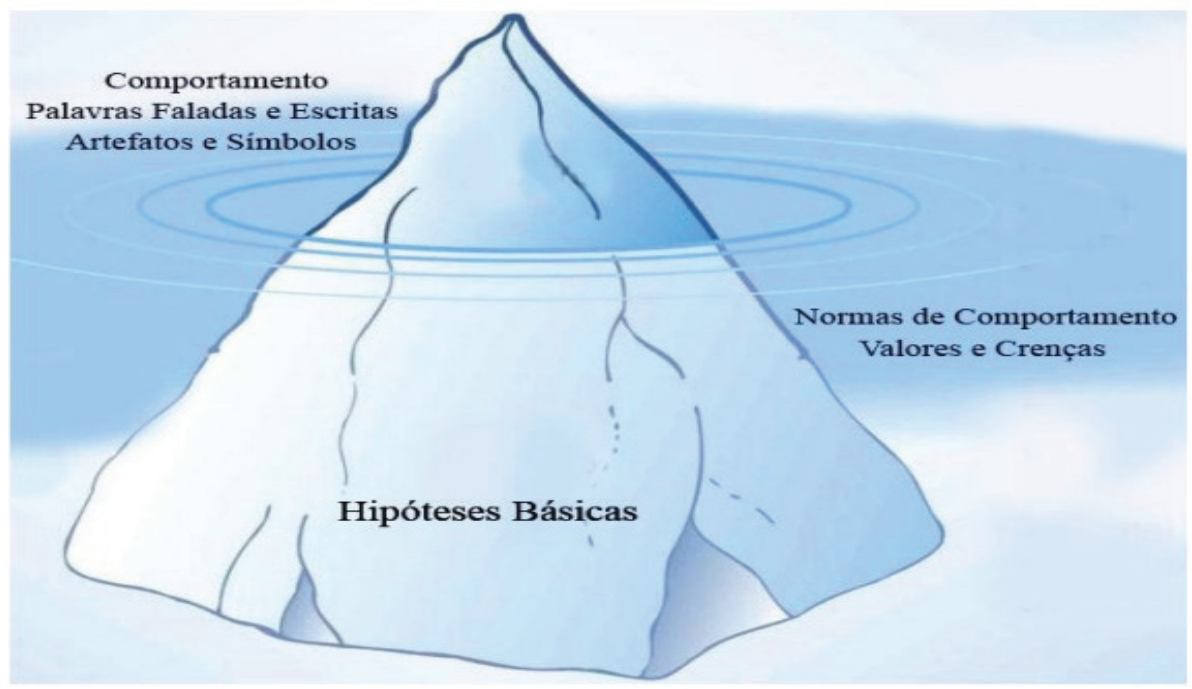

Figura 1: Metáfora da Cultura como Iceberg

Fonte: Friedman e Antal (2005, p.72). 
A figura 1 pode auxiliar na compreensão de que um ambiente de trabalho intercultural, o comportamento desses indivíduos (outros) - pode parecer inusitado, ilógico ou até mesmo atroz. Tal negligência tende a trazer inúmeras implicações de diversas naturezas para a organização sejam de imagem, relacionais, financeiras e de produção. Bueno e Freitas (2018) salientam que em equipes homogêneas, é mais fácil compreender o que os outros estão tentando dizer, em equipes culturalmente diversas, as falhas de percepção, de comunicação e de interpretação emergem a todo momento.

Essas variáveis emergem a importância da efetiva gestão intercultural, pois, a indução de interpretações insuficientes ou ainda distorcidas da realidade, sobretudo, quando o próprio contexto é menosprezado, podem gerar dificuldades na gestão. Segundo os autores, mesmo os profissionais que possuem habilidades, atributos e conhecimentos que lhes permitam agir de forma eficaz em um ambiente intercultural, certamente encontrarão variáveis do ambiente que representem dificuldades na eficácia da gestão intercultural. Logo, o aprimoramento das habilidades e conhecimento, são essenciais para reduzir os conflitos interculturais existentes no ambiente de trabalho (HAJRO; GIBSON, PUDELKO, 2015; BUENO, FREITAS, 2018).

Demonstradas algumas concepções teóricas sobre a gestão da interculturalidade nas organizações, a próxima seção apresenta-se o escopo metodológico que possibilitou a realização do presente estudo.

\section{Procedimentos metodológicos}

Para realizar deste trabalho cujo o objetivo proposto foi o de analisar a percepção de gestores em relação à gestão intercultural em organizações no setor da agroindústria situadas na região Sudoeste do Estado do Paraná, optou-se por utilizar uma abordagem qualitativa, do tipo descritivo, alinhado as técnicas de observação e entrevistas devido à propriedade com que esses instrumentos penetram na complexidade de um problema.

O enfoque qualitativo, como argumentam Vieira e Rivera (2012) e Sampieri, Collado e Lucio (2013), é utilizado quando se busca entender a perspectiva dos indivíduos sobre fenômenos que os rodeiam, sobre suas experiências, opiniões, ponto de vista, ou seja, 
como os participantes percebem de modo subjetivo sua realidade. A pesquisa de cunho descritivo, conforme Bertucci (2011) tem como objetivo primordial a descrição das características de determinada população ou fenômeno ou, então, o estabelecimento de relações entre variáveis

Na Figura 2 apresenta-se de maneira esquemática e sintético os procedimentos metodológicos da abordagem qualitativa, que serão detalhados e descritos nas sessões seguintes.

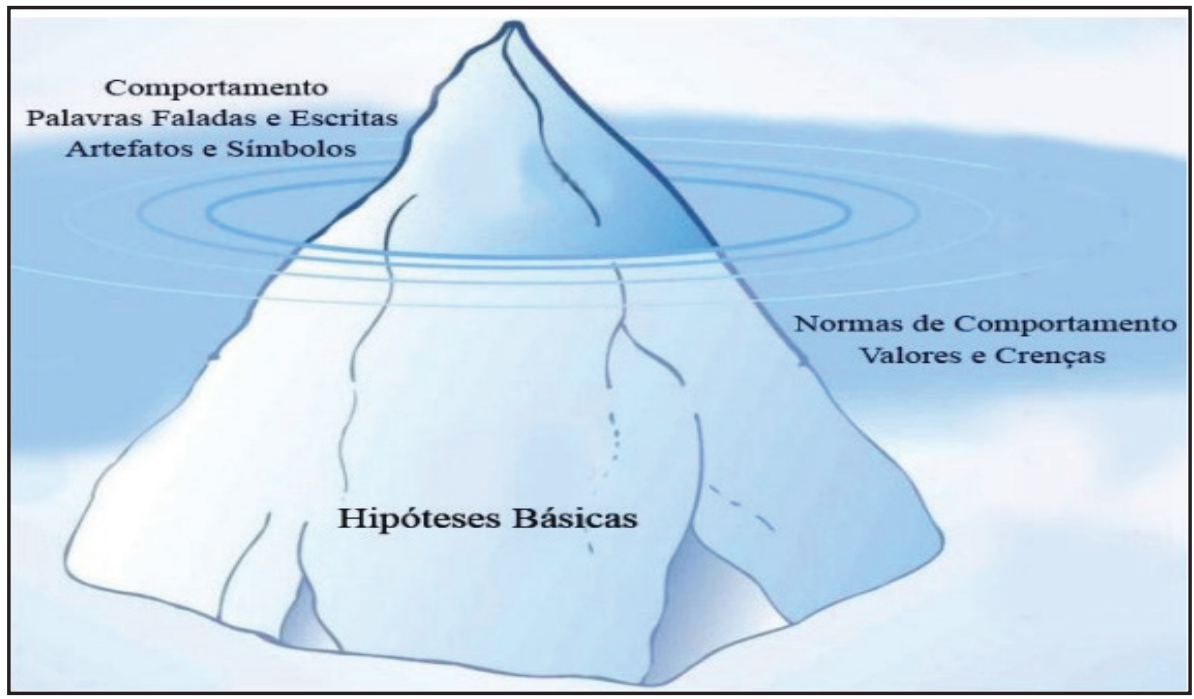

Figura 2 - Procedimentos metodológicos da abordagem qualitativa Fonte: Elaborado pelas autoras.

\subsection{Participantes da Pesquisa}

O objeto de estudo foram três organizações no segmento da agroindústria situadas na região Sudoeste do Paraná, que por questões éticas tanto a identificação das organizações como dos participantes não serão revelados, assim denominadas de organização A, B e C, respectivamente, que foram escolhidas por possuírem trabalhadores estrangeiros vindos do Haiti e também pelo acesso e aceitação em participar da pesquisa. Sendo assim, a população desta pesquisa foi constituída por três gestores de cada organização objeto do estudo. A escolha dos participantes da pesquisa ocorreu, 
em virtude, dos profissionais gerirem equipes interculturais nas três organizações participantes.

\subsection{Instrumento e coleta de dados}

Para a coleta de dados optou-se por utilizar entrevistas semiestruturadas com os três gestores selecionados das organizações $\mathrm{A}$, B e C. A escolha da técnica de entrevista respalda-se na visão de Belk, Fischer e Kozinets (2013) que sugerem que a entrevista vem se popularizando como forma de coleta de dados qualitativos, em pesquisas sobre comportamento nas ciências sociais, seja ela considerada aberta, em profundidade ou semiestruturada.

O roteiro das entrevistas foi agrupado em três blocos, sendo: o primeiro correspondente a formação acadêmica e trajetória profissional; no segundo discorre-se sobre as práticas profissionais das atividades exercidas na organização, e no terceiro com questões voltadas a interculturalidade no ambiente de trabalho.

A elaboração do roteiro das entrevistas foi adaptada do modelo utilizado por Wagner (2009) e Craide (2011) composto por cinco perguntas fechadas e quinze abertas. Triviños (2008) destaca que o tipo de entrevista mais adequado para a pesquisa qualitativa se aproxima dos esquemas mais livres, menos estruturados, em que não há imposição de uma ordem rígida de questões.

Logo após, a aprovação do projeto de pesquisa pelo Comitê de Ética da Universidade (Protocolo CEP-UTFPR - CAAE: 73355217.5.0000.5547), este foi direcionado às organizações participantes da pesquisa para as respectivas avaliações e análises da viabilidade de execução do estudo. A partir da autorização dos comitês envolvidos é que se deu início a coleta de dados, sendo realizado no período entre o mês de outubro e dezembro de 2017. As entrevistas ocorreram individualmente, no próprio local de trabalho dos participantes da pesquisa, foram repassadas as informações e sanado dúvidas relativo a pesquisa. Ao estarem de acordo em integrar e colaborar com o estudo, assinaram o TCLE, e entregues suas respectivas cópias. As entrevistas tiveram uma duração média de 1h gravadas, transcritas e posteriormente analisadas. 


\subsection{Análise dos dados}

Para o tratamento dos dados qualitativos foi aplicada o método de análise de conteúdo, que, no entendimento de Minayo (2010) assevera ser o método mais frequente adotado na análise de dados desta natureza. Para Bardin (2016, p. 15), a análise de conteúdo consiste em "um conjunto de instrumentos metodológicos cada vez mais sutis em constante aperfeiçoamento, que se aplica a "discursos" (conteúdos e continentes) extremamente diversificados".

A utilização do método de análise de conteúdo requer algumas categorias que contribuirão, para a interpretação e inferências dos dados coletados sendo definidas baseada no aporte teórico. Assim, a categorização, conforme enfatiza Bardin (2016, p. 147) “é uma operação de classificação de elementos constitutivos de um conjunto por diferenciação e, em seguida, por reagrupamento segundo o gênero (analogia), com os critérios previamente definidos". Franco (2008) explica que estas categorias podem ser criadas "a priori", ou seja, são pré-determinadas em função da busca a uma resposta específica do pesquisador. Ou podem não ser definidas "a priori", emergindo do discurso, do conteúdo das respostas e exigem constante retorno ao material coletado e à teoria. Desse modo, identificou-se as categorias analíticas a priori, sendo designadas como: reconhecimento do outro, diferença cultural e identidade, com base em Cox Jr. (1994); Freitas (2000, 2009); Matveev \& Nelson (2004); Bueno \& Freitas (2012); Rambo \& Diehl (2015); Hajro, Gibson \& Pudelko (2015); Bueno \& Freitas (2018).

O desenvolvimento da análise de conteúdo ocorreu em três fases, sendo a primeira denominada como formulação, ou seja, foi definido as categorias de análise com base no aporte teórico, transcrição dos dados e criação de arquivo base para as informações. A segunda fase a leitura das entrevistas, tal como a seleção do conteúdo das entrevistas conforme a categoria, e a terceira é a análise que tem como objetivo realizar as inferências, e compreensões das falas, neste sentido, o uso de figuras e gráficos auxiliam para o entendimento dos resultados obtidos. Diante do exposto, na próxima seção apresenta-se os resultados das análises dos dados obtidos no estudo. 


\section{Apresentação e análise dos resultados}

Nesta seção, apresenta-se os resultados do estudo considerando o objetivo proposto na seção introdutória. Os resultados foram ponderados em quatro subseções. A primeira subseção, contém uma breve caracterização dos participantes da pesquisa. As três subseções seguintes, correspondem a análise das categorias analíticas definidas a priori: reconhecimento do outro, diferença cultural e identidade.

\subsection{Perfil dos participantes da pesquisa}

A explanação da caracterização do perfil dos pesquisados consiste nas especificações quanto ao gênero, faixa etária, nacionalidade, estado civil e formação acadêmica, conforme descrito no Quadro 1. Destaca-se que os gestores participantes não foram identificados, respeitando as questões éticas da pesquisa, e, contudo, foram atribuídos códigos, como E - entrevistado seguido da numeração.

Quadro 1 - Caracterização do perfil dos participantes

\begin{tabular}{|l|l|l|l|l|l|}
\hline $\begin{array}{l}\text { Entre- } \\
\text { vistado }\end{array}$ & Gênero & Faixa Etária & $\begin{array}{l}\text { Nacionali- } \\
\text { dade }\end{array}$ & $\begin{array}{l}\text { Estado } \\
\text { Civil }\end{array}$ & $\begin{array}{l}\text { Formação Aca- } \\
\text { dêmica }\end{array}$ \\
\hline E1 & Masculino & $\begin{array}{l}\text { Entre 36 a } 40 \\
\text { anos }\end{array}$ & Brasileiro & Separado & $\begin{array}{l}\text { Engenharia de } \\
\text { Alimentos }\end{array}$ \\
\hline E2 & Feminino & $\begin{array}{l}\text { Entre 26 a } 30 \\
\text { anos }\end{array}$ & Brasileira & Solteira & Administração \\
\hline E3 & Masculino & $\begin{array}{l}\text { Entre 36 a } 40 \\
\text { anos }\end{array}$ & Brasileiro & Casado & $\begin{array}{l}\text { Engenharia da } \\
\text { produção }\end{array}$ \\
\hline
\end{tabular}

Fonte: Dados da Pesquisa.

A partir das informações contidas no Quadro 1, constata-se que o gênero masculino é predominante no âmbito da gestão, referente as organizações pesquisadas. Percebe-se que a maioria dos entrevistados tem entre 36 a 40 anos de idade, correspondendo a uma idade média de 38 anos. Tomando como referências essas faixas etárias da distribuição dos gestores das organizações, apenas uma tem entre 26 a 30 anos. Pressupõe, que a ocupação em cargos pro- 
fissionais mais qualificados em nível de gestão, caracteriza-se pela maior experiência, qualificação e nível de escolaridade. Por outro lado, evidencia-se certa mudança cultural em relação ao passado, quando os cargos de gestão eram ocupados por pessoas com faixa etária superior a 40 anos, e a presença gradativa das mulheres nos cargos de gestão (VEBER et al, 2016).

Todos são brasileiros (a), com estado civil distintos (separado, solteira, casado). Referente a formação acadêmica todos (a) possuem formação em nível superior. A característica comum aos participantes da pesquisa é a formação continuada seja em nível tecnólogo ou de especialização. O gestor contemporâneo, sobretudo, aquele que é responsável pela gestão intercultural precisa estar em constante capacitação e atualizando os conhecimentos, como corrobora Ruas et al (2005, p. 94) "o gestor intercultural na atualidade, precisa ter visão sistêmica e estratégica, domínio pessoal, capacidade de trabalhar em equipe, possuir habilidades humanas e interculturais, flexibilidade, capacidade de inovação, comportamento ético, capacidade de aprender e de liderar". Desse modo, Paula e Sampaio (2018) afirmam que, cenários interculturais demandam mais do que conhecimento e a capacidade de se comunicar em outros idiomas, mas também de como interpretar, mediar e abordar modelos culturais múltiplos que coexistem em um ambiente intercultural.

A partir dos relatos colhidos identificou-se os principais aspectos relacionados às percepções de gestores relativo a gestão intercultural, mantendo-se a perspectiva dos entrevistados. Os resultados da análise de conteúdo dos relatos dos gestores são apresentados a seguir, organizados nas três categorias analíticas: reconhecimento do outro, diferença cultural e identidade.

\subsection{Reconhecimento do outro}

Em um ambiente intercultural, de acordo com Machado e Hernandez (2003) é relevante a disseminação da ideia da alteridade, que consiste na relação do indivíduo com o outro, sendo por meio desta troca que cada pessoa constrói ou reconstrói sua identidade e o reconhecimento do outro favorece a compreensão de si mesmo. As relações que são construídas, a partir do contato com o "outro" tendem a agregar em conhecimento, aprendizagem, ampliação de 
visão de mundo, bem como contribui na construção de um ambiente organizacional mais diversificado e plural.

A interculturalidade realiza-se no momento em que diferentes culturas passam a conviver, a interagir num processo capaz de criar e recriar sentido para os atores envolvidos, a partir da necessidade de se estabelecer uma base de comunicação entre diferentes que habitam o mesmo espaço, requerendo compreensão de ambas as partes a respeito do que os une nesse diálogo (BARBOSA, VELOSO, 2009). A interação, a troca, o compartilhamento de informação, experiências, conhecimento, agregam o processo intercultural.

Por outro lado, Freitas (2000; 2009) explica que o ser humano tem a necessidade de fazer parte de um algum grupo, clã, tribo, que lhes garantem o reconhecimento de si como parte de algo maior, compartilhando o segredo, o código, o inacessível ao estrangeiro. Ainda frisa que, o contato com outra cultura expõe o indivíduo a riscos, à consciência de perdas e o coloca em confronto consigo mesmo; o desconhecimento dos artefatos mais primários pode ocasionar um abalo em sua autoestima pelo simples fato de sentir-se um inútil. Por conseguinte, reforça-se o preparo técnico e humano que os gestores precisam possuir, tendo em vista, as inúmeras variáveis que engloba a gestão de equipes interculturais.

A gestão intercultural nas organizações apresenta contribuições e aprendizagens no campo profissional e pessoal, a partir das trocas que são estabelecidas e do reconhecimento do outro. Os trechos dos relatos no Quadro 2 ilustram tais características e especificidades da proximidade com os trabalhadores migrantes. 


\section{Quadro 2 - Reconhecimento do outro: características e especificidades}

\begin{tabular}{|c|c|}
\hline $\begin{array}{l}\text { Entrevista- } \\
\text { dos }\end{array}$ & Trechos dos Relatos \\
\hline E1 & $\begin{array}{l}\text { Olha com certeza a gente aprendeu, por exemplo, assim } \\
\text { falando profissionalmente hoje a forma com que eu } \\
\text { lido com eles eu aprendi bastante no início lá eu tive } \\
\text { um pouco dificuldade em me adaptar a gente acabava } \\
\text { auxiliando muito, auxiliando e às vezes não cobrava neh, } \\
\text { não cobrava da mesma forma que a gente cobra dos bra- } \\
\text { sileiros daí depois eu percebi que isso foi ruim, por que } \\
\text { depois a gente sentiu que estava fazendo uma gestão de } \\
\text { uma maneira diferente pro mesmo público neh, se eram } \\
\text { diferentes sim neh, mas que não precisava ser feito isso, } \\
\text { precisavam ser tratados iguais neh, então aprendi com } \\
\text { isso, aprendi conviver e amadureci isso também neh, } \\
\text { (...) e a partir do momento que eu mudei essa minha } \\
\text { postura em relação a isso eu percebi que os resultados } \\
\text { em relação a eles de rendimento, de trabalho, de produ- } \\
\text { tividade se equiparou aos brasileiros, se equiparou assim } \\
\text { e é bem positivo sabe. É outras coisas assim, por exem- } \\
\text { plo, assim eles são muito ligados a questão de respei- } \\
\text { tar o próximo sabe, eu vejo isso bem forte neles é uma } \\
\text { coisa que assim que muitas a gente para e pensa neh e } \\
\text { repensa um pouco até nossos conceitos de vida neh. }\end{array}$ \\
\hline E2 & $\begin{array}{l}\text { Eu acho que a diversidade neh ela faz a gente ser um } \\
\text { pouco mais aberto a diversidade por que a gente começa } \\
\text { a conviver com pessoas que são diferentes você acaba } \\
\text { sendo mais receptivo neh, e foi um aprendizado eu acho } \\
\text { pra todo mundo neh. }\end{array}$ \\
\hline E3 & $\begin{array}{l}\text { (...) não vou dizer pra você em todos mas esse brilho no } \\
\text { olhar essa vontade de trabalhar ahhh a força de von- } \\
\text { tade que eles tem. Ainda mais quando são elogiados } \\
\text { pelo trabalho que eles fazem (...) a cultura é totalmente } \\
\text { diferente, você tem que se adaptar aquela nova cultura e } \\
\text { aí você começar a trabalhar numa empresa aonde lá não } \\
\text { existia essa empresa, totalmente diferente o ramo ahh. } \\
\text { Então acredito que a aprendizagem é a força de vontade } \\
\text { que eles têm. }\end{array}$ \\
\hline
\end{tabular}

Fonte: elaborado pelas autoras. 
A proximidade com trabalhadores migrantes, denota a importância do aperfeiçoamento profissional, pois como revela o gestor E1, "há dificuldade na adaptação" de gerir equipes interculturais, especialmente quando a gestão inclui trabalhadores estrangeiros, vindos de outro país. Na perspectiva de Freitas (2009), Paula \& Sampaio (2018), a qualificação profissional constitui um diferencial no mercado, além de aprimorar as habilidades e técnicas profissionais. É essencial ao gestor possuir conhecimento e entendimento de hábitos, costumes e tradições de um dado povo, para que se instaure relações profundas, sólidas e duráveis no ambiente corporativo.

Percebe-se a necessidade de reconhecer o "outro", diante das diferenças que os compõem, relativo a cultura, pensamento, valores, ideologias. Como evidencia Freitas (2009, p. 80) "o reconhecimento do outro é um elemento fundador da convivência intercultural que se impõe na vida social e organizacional nos dias de hoje". O reconhecimento do outro como diferente é um avanço para que haja melhoria da convivência de pessoas, sociedades e organizações, pois favorece o respeito mútuo, a diminuição de estereótipos, incompreensões e dificuldades de interação. Nesse sentido, cabe ao líder ter a sensibilidade de compreender diferentes culturas presentes no cenário organizacional, bem como promover a interação entre os membros.

Outrossim, aumenta a qualidade das decisões tomadas no ambiente de trabalho, além da tendência à formação de um ambiente cada vez mais qualificado, diverso, porém, mais sujeito a conflitos e exclusão (FREITAS, 2008, 2009). Entretanto, para que essa aproximação ocorra é necessário o estabelecimento da comunicação, como frisa Bueno e Freitas (2018, p. 104) “(...) entre os indivíduos que ajudará a diminuir o desconhecimento do outro. Como não se sabe o que é similar, e o que é diferente, será por meio dos diálogos que será construído a ponte entre os indivíduos".

Destarte, Barbosa e Veloso (2009, p. 171) afirmam que a gestão intercultural se caracteriza pelo "entender e lidar com o outro". Todavia, as organizações não estabelecem formas de como esse encontro deve acontecer. Para tanto, esse oficio é direcionada à gestores que irão encarar esta experiência. Os autores ainda acrescentam que “(...) tais gestores seriam aqueles que possuem facilidade para lidar com a diferença, e que, de preferência, gostam deste desafio" 
(BARBOSA, VELOSO, 2009, p. 171). O encurtamento do reconhecimento do "outro" demanda em muitas vezes, o empenho do gestor em buscar a qualificação profissional, em termos de aprender um novo idioma, por exemplo, objetivando a melhoria da comunicação, especialmente nos casos, em que há trabalhadores de outras nacionalidades no ambiente de trabalho.

Com base nas falas dos Entrevistados E1, E2 e E3 contidas no Quadro 3 revelam os desafios para uma adequada gestão de equipes interculturais.

\section{Quadro 3 - Reconhecimento do outro: desafios}

\begin{tabular}{|l|l|}
\hline Entrevistados & Trechos dos Relatos \\
\hline E1 & $\begin{array}{l}\text { (...) tentar entender eles, de tentar inserir eles na } \\
\text { equipe neh, acolher eles fazer com que eles se } \\
\text { sentissem acolhido e fazer essa ligação deles com } \\
\text { a nossa equipe que já existia até então neh. }\end{array}$ \\
\hline E2 & $\begin{array}{l}\text { (..) um dos desafios mais perceptíveis é que } \\
\text { quando um migrante haitiano saiu é digo se des- } \\
\text { ligou da empresa, a primeira vez, aí alguns são } \\
\text { muito parceiro neh então eles se queimam uns } \\
\text { pelos outros e acabaram saindo também }\end{array}$ \\
\hline $\begin{array}{l}\text { (...) nesses três anos que eu estou trabalhando, ge- } \\
\text { rindo uma equipe intercultural tá, e pra mim foi } \\
\text { assim, foi uma coisa nova, uma cultura diferente } \\
\text { e na verdade ahhh a gente mais aprende com } \\
\text { eles do que ensina eles tá. Eles tentam nos passar } \\
\text { a cultura deles, e nós da melhor forma possível } \\
\text { a gente também tenta aprender. Tenta aprender } \\
\text { algum (algum) dialeto deles, a forma que eles } \\
\text { ahhh se conversam também ahhh até para poder } \\
\text { facilitar esse convívio. }\end{array}$ \\
\hline
\end{tabular}

Fonte: elaborado pelas autoras.

Os desafios elencados pelos gestores entrevistados, remetem a responsabilidade da inserção, principalmente referente a trabalhadores estrangeiros, ao qual alguns não exerciam tais atividades laborais em seus países de origem (CARVALHO, 2017). Desse 
modo, o desafio tende a ser mais complexo, uma vez que, além de ser necessário inserir tais trabalhadores no ambiente de trabalho com demais colegas, ainda é preciso disponibilizar profissionais para auxiliar e coordenar as atividades laborais designados a tais funcionários.

Ao inserir trabalhadores de culturas distintas na esfera das organizações é necessário antes de tal ação, um preparo técnico e humano para trabalhar com tais complexidades de inserção, adaptação cultural, comunicação, interferências no âmbito das relações pessoais, uma vez que, existem lacunas tanto para os gestores que estarão à frente da administração da equipe, quanto para o trabalhador que enfrenta uma diversidade de mudanças de ordem social, econômica, cultural oriunda da mobilidade para o país de destino.

No contexto global, as diferenças culturais podem exercer influências na assimilação, institucionalização e adaptação de práticas de gestão, podendo afetar a performance organizacional (CANCLINI, 2005; FREITAS, 2008; CREIDE, SILVA, 2012; ARANHA, 2018). Outro elemento que merece atenção em relação a equipes interculturais relaciona-se ao fato de que diferentes identidades de membros de um time podem desencadear sentimentos de negatividade, isolamento e estereótipos. Todavia, a implementação de ações de integração e envolvimento emocional e valorização pode ser positivamente ligada ao compartilhamento do conhecimento em equipes de culturas distintas (HAJRO; GIBSON; PUDELKO, 2015; BUENO; FREITAS, 2018).

Ademais, constata-se sobre a dificuldade da organização em gerir os demais trabalhadores quando do desligamento dos migrantes, ao mencionar que "alguns se queimam uns pelos outros e acabam saindo também"; tornando uma situação complexa, haja vista, que a organização adentra em um processo cíclico de rotatividade de funcionários, dificultando na otimização dos resultados organizacional.

\subsection{Diferença cultural}

A interculturalidade leva a reflexão sobre a realidade do Brasil, sendo este país de vasta dimensão continental, alta diversidade cultural: será que para perceber a diferença cultural, os profissionais precisam atravessar fronteiras. Ao migrar entre Estados no Brasil ele 
não vivencia diferenças culturais, econômicas, sociais, educacionais, políticas, climáticas, e torna-se um estrangeiro dentro do seu próprio país? (CRAIDE, 2011). Essas indagações são relevantes à medida que, as organizações busquem melhorias nas estratégias de gestão, levando em consideração as diferenças culturais existentes no ambiente laboral. A diferença cultural, se tratando de migrantes haitianos é percebida em um primeiro momento, na comunicação, conforme verificadas nos trechos das falas selecionadas a seguir no Quadro 4.

\section{Quadro 4 - Diferença cultural: comunicação}

\begin{tabular}{|l|l|}
\hline Entrevistados & Trechos dos Relatos \\
\hline E1 & $\begin{array}{l}\text { (...) nesse sentido assim neh acabava dificultando essa } \\
\text { relação intercultural, no sentido da língua neh tinha } \\
\text { dificuldade na comunicação então acabava às vezes } \\
\text { assim não se entendendo direito, às vezes até por não } \\
\text { querer se comunicar alguns ficavam meio receoso deles } \\
\text { ficarem falando. }\end{array}$ \\
\hline E2 & $\begin{array}{l}\text { (...) o que mais dificulta a vida deles nas empresas é a } \\
\text { comunicação, a maioria deles não fala o português bem } \\
\text { então eles têm bastante dificuldade em se comunicar a } \\
\text { forma neh deles pensar e agir também é diferente um } \\
\text { pouco neh do brasileiro, então eles têm uma dificulda- } \\
\text { de de interação isso é nítido. }\end{array}$ \\
\hline E3 & $\begin{array}{l}\text { (...) quando nos iniciamos essas contratações alguns } \\
\text { já falavam português e sempre que tem alguém com } \\
\text { dificuldade, nós sempre chamamos alguém pra ajudar } \\
\text { a traduzir e às vezes na linguagem você não entende, } \\
\text { mas nos sinais tu consegue entender tá e essa comuni- } \\
\text { cação é fácil. }\end{array}$ \\
\hline
\end{tabular}

Fonte: elaborado pelas autoras.

Com base nas falas de E1, E2, e E3 percebe-se que a dificuldade de inserção dos trabalhadores estrangeiros, situa-se na comunicação. O desconhecimento da língua portuguesa impede a intercomunicação representando a porta de inconvenientes na qualidade de vida de muitos migrantes, seja para pedir emprego, compreender as normas do ambiente de trabalho, no momento de se relacionar com os 
brasileiros. E a falta de comunicação é um agravante, em situações que por exemplo, envolvam a escolha da admissão de trabalhadores que não tenham conhecimento do idioma, neste caso, o português.

De acordo com Pires (2013) a comunicação intercultural tem, mais do que nunca, uma importância fundamental. A aproximação das pessoas por meio do uso das novas tecnologias e da abertura de fronteiras tornou a compreensão do outro um assunto ainda mais relevante. A dinâmica da comunicação intercultural não se finda na ideia de encontrar uma língua comum de entendimento. A preparação técnica dos gestores que irão gerir equipes interculturais é importante para propiciar uma interação que minimize os conflitos, a começar pelo linguístico.

Ocorre, entretanto, que diferenças culturais podem diminuir a eficiência de tais equipes, caracterizando-se em barreiras, como por exemplo, a conversação e argumentação num idioma que não é o nativo, a compreensão de ideias oriundas de percepções culturais distintas, além de uma possível falta de integração e convivência (BANISKI, CIESLAK, 2018). Para minimizar essas barreiras, a organização pode propor cursos de curta duração de português, com o intuito de melhoria da comunicação entre os membros da organização, bem como para maximizar os resultados corporativos.

A dimensão da interculturalidade julga ser necessária uma comunicação comum visando a convivência mútua dos envolvidos (BARBOSA, VELOSO, 2009). Para além de estabelecer um diálogo, a comunicação é a estrutura de suporte para que as interações, socialização e compartilhamento ocorram. A cultura organizacional é disseminada por meio da comunicação, pois os compartilhamentos de informações se processam por meio de jornais internos, e-mails, newsletters, reuniões, murais, encontros individuais e a comunicação é o eixo norteador de tais práticas. Este fator demanda um planejamento prévio de como estabelecer um diálogo compreensível, principalmente em equipes interculturais, atentando-se para membros que não são nativos. 


\subsection{Identidade}

A noção de identidade é essencial para o estudo da interculturalidade. Segundo, Warnier (2000, p. 16) “a identidade é definida como um conjunto dos repertórios de ação, de língua e de cultura que permitem a uma pessoa reconhecer sua vinculação a certo grupo social e identificar-se com ele". Nos estudos interculturais é frequente o destaque para às consequências do choque cultural e ao encontro com "o outro". "O outro" tem sido, ao mesmo tempo, o centro dos estudos que abordam a temática da interculturalidade.

Para Guitel (2004) a qualidade do que é diferente está intimamente ligada com questões de identidade. Para ele, as pessoas possuem muitas identidades, entretanto, é a identidade cultural a mais importante. Identidades variam de acordo com o número de pessoas que compartilham delas, seu grau de importância na sociedade, a intensidade da comunicação entre as pessoas no grupo em que se relacionam. Constata-se que as identidades são reveladas no momento em que as pessoas se encaram e interagem.

A identidade está ligada ao reconhecimento do "Eu". Como menciona Dias (2011), o reconhecimento ou não reconhecimento por parte do outro é central no processo de construção da identidade. Ao ingressarem em uma organização, indivíduos com características diversas se unem para atuar dentro de um mesmo sistema sociocultural em busca de objetivos pré-determinados. Com base, nos pressupostos dos autores é possível entender que a cultura e a língua são elementos primordiais da identidade de uma sociedade e que influi no relacionamento com pessoas de outras culturas e outros ambientes sociais.

Os trechos das entrevistas a seguir demonstradas no Quadro 5 ilustram iniciativas dos gestores para o compartilhamento de práticas culturais dos trabalhadores migrantes, evidenciando o avivamento de suas raízes culturais, no ambiente de trabalho. 


\section{Quadro 5 - Identidade: interação}

\begin{tabular}{|c|c|}
\hline Entrevistados & Trechos dos Relatos \\
\hline E1 & $\begin{array}{l}\text { (...) a gente tem várias ações café de boas-vindas no } \\
\text { início do ano, confraternização no final do ano, eles } \\
\text { participam de todas as confraternizações, todas as } \\
\text { coisas iguais então festa de final de ano eles vão igual } \\
\text { aos brasileiros, então tudo que a gente faz de ações } \\
\text { dentro do ano eles participam de forma igual e são } \\
\text { bem participativos. }\end{array}$ \\
\hline E2 & $\begin{array}{l}\text { (...) eles adoram a questão da banana verde frita, é } \\
\text { um prato típico deles lá, então eles fazem lá de vez } \\
\text { em quando neh não todo dia, mas fazem o prato lá } \\
\text { identifica lá e eles gostam disso. Essa semana faz o } \\
\text { que, não essa semana, faz um mês mais ou menos a } \\
\text { gente fez um evento lá na empresa uma espécie de } \\
\text { um workshop assim neh, uma apresentação assim pra } \\
\text { mostrar as culturas que se tem dentro da empresa, } \\
\text { todas as culturas alemã, italiana, a própria brasileira } \\
\text { neh e também a cultura haitiana neh, então cada um } \\
\text { pode mostrar um pouquinho o que se tem de marca } \\
\text { em cada cultura neh }\end{array}$ \\
\hline E3 & $\begin{array}{l}\text { (...) nós temos essa boa comunicação também ahhh } \\
\text { em eventos como o CIPAT tá, também temos em } \\
\text { alguns eventos, que são eventos da qualidade nos } \\
\text { tivemos a primeira semana da qualidade há vinte } \\
\text { poucos dias atrás, e ai essa (essa) esse estreitamento } \\
\text { entre brasileiros e estrangeiros tem um palco que se } \\
\text { é montada ali na empresa pra CIPAT pra semana da } \\
\text { qualidade e nesse mesmo palco se divide ali a cultura } \\
\text { brasileira e haitiana. Ahh através de cantos que eles } \\
\text { preparam ali na mão pra poder começar a cantar, fa- } \\
\text { zem paródia e brasileiros participam da paródia deles } \\
\text { tentando cantar que é difícil um pouco, um pouco não } \\
\text { é muito difícil a língua deles e eles também cantam } \\
\text { com nós os brasileiros. }\end{array}$ \\
\hline
\end{tabular}

Fonte: elaborado pelas autoras.

Como se identifica nos relatos apresentados no Quadro 5, há um esforço dos gestores em propiciar espaços e momentos de in- 
teração, de troca e reconhecimento cultural, essas ações tendem a ser benéficas para o ambiente corporativo, uma vez que, favorece a aproximação entre o "Eu" e o "Outro", para a compreensão das peculiaridades existentes entre culturas distintas. Do mesmo modo, que demonstra o reconhecimento e afirmação da identidade cultural dos migrantes, a partir de ações que promovam a apresentação de seus costumes culturais.

Partindo do pressuposto de que a identidade se constitui na relação com o outro, é preciso que as equipes de trabalho estejam próximas, que haja interação entre os membros pois, é uma oportunidade de conhecer o outro, configurando uma experiência rica e importante para a carreira de cada trabalhador, tal como amplia a visão de mundo e daquilo que é diferente. Na mesma linha Alsina (2004, p. 55) diz que "a identidade é uma construção cultural fruto da socialização e da interação social", o que mostra que a identidade é construída pela comparação e diferenciação.

Do mesmo modo, que a identidade não pode ser fixa; pois é constituída por uma "rede" de fios entrelaçados entre as diferentes relações que vai se constituindo ao longo de sua interação no meio em que convive, seja familiar, no trabalho, na sociedade, escola. Com indivíduos de diferentes partes do mundo eventualmente conectados, com grande volume de troca de informações, e com referências identitárias mais horizontais e fluidas, que permitem que pessoas atreladas a diferentes lugares compartilhem referenciais simbólicos em comum (NASI, 2015). Assim, no ambiente em que coexistem grupos de identidades culturais diferentes, os gestores necessitam adotar medidas administrativas que garantam que as particularidades pessoais e de grupos sejam utilizados como recursos para melhorar o desempenho econômico da organização.

No Quadro 6 retoma-se de forma mais sintetizada os principais achados da pesquisa, bem como, apresenta-se algumas proposições para melhoria da gestão da temática abordada neste estudo. 


\section{Quadro 6 - Contribuições do estudo}

\begin{tabular}{|c|c|c|}
\hline Categorias & Percepções Gerais & Proposições \\
\hline $\begin{array}{l}\text { Reconheci- } \\
\text { mento do } \\
\text { outro }\end{array}$ & $\begin{array}{l}\text { Ausência de conheci- } \\
\text { mento, principalmente } \\
\text { o cultural; } \\
\text { Inabilidade técnica; } \\
\text { Falta de empatia; } \\
\text { Dificuldade de intera- } \\
\text { ção. }\end{array}$ & $\begin{array}{l}\text { Preparo prévio dos gestores, } \\
\text { anterior a integração dos tra- } \\
\text { balhadores migrantes; } \\
\text { Proporcionar minicursos sobre } \\
\text { a cultura do Haiti; } \\
\text { Acompanhar profissionais } \\
\text { haitianos nos seus locais de } \\
\text { trabalho de maneira contínua; } \\
\text { Propiciar contato individual } \\
\text { com trabalhadores migrantes, } \\
\text { a fim de levantar suas limi- } \\
\text { tações frente as atividades } \\
\text { executadas. }\end{array}$ \\
\hline $\begin{array}{l}\text { Diferença } \\
\text { cultural }\end{array}$ & Comunicação. & $\begin{array}{l}\text { Propor aulas de português } \\
\text { para migrantes haitianos, no } \\
\text { ambiente de trabalho, em ho- } \\
\text { rário acessível e compatível ao } \\
\text { público-alvo. }\end{array}$ \\
\hline Identidade & $\begin{array}{l}\text { Trocas culturais entre } \\
\text { trabalhadores brasileiro } \\
\text { e haitianos; } \\
\text { Aproximação com o } \\
\text { "outro". }\end{array}$ & $\begin{array}{l}\text { Elaboração de cronograma } \\
\text { com eventos que proporcio- } \\
\text { nem e intensifiquem as trocas } \\
\text { culturais, que reconheçam e } \\
\text { afirmem a cultura peculiar de } \\
\text { cada cultura. } \\
\text { Oportunizar encontros com } \\
\text { brasileiros e haitianos, nos } \\
\text { seus respectivos setores, com o } \\
\text { intuito de trocas de experiên- } \\
\text { cias profissionais. }\end{array}$ \\
\hline
\end{tabular}

Fonte: Dados da Pesquisa.

Em conformidade com as percepções gerais de cada categoria analítica, descritas no Quadro 6, tais como são delineadas algumas proposições, com o intuito de melhoria no âmbito da gestão intercultural, uma vez que, a mobilidade de pessoas no cenário organizacional tem ocorrido corriqueiramente. Portanto, o que se visou a destacar é que as organizações, ao decidirem contratar trabalhadores, 
especialmente, estrangeiros devem atentar-se para a premência de elaborar e implementar políticas e estratégias de gestão intercultural. Ao desenvolver práticas de gestão intercultural, orientada a integração e interação dos membros da equipe, a organização tende a reduzir possíveis transtornos que podem manifestar-se a partir dos estranhamentos culturais destes indivíduos.

\section{CONSIDERAÇõES FINAIS}

No percurso realizado neste artigo foi ressaltado a importância da atualização e qualificação de gestores, especialmente aqueles que trabalham com equipes interculturais. Considerando uma temática que não se pode negligenciar em um contexto em que as relações, cada vez mais, são globais e interconectadas. Portanto, acredita-se que o presente trabalho possa contribuir para tal reflexão, ao procurar compreender a gestão intercultural no ambiente organizacional. Especificamente, o artigo procurou analisar a percepção de gestores em relação à gestão intercultural em organizações no setor da agroindústria situadas na região Sudoeste do Estado do Paraná. Nota-se, que não apenas no processo de expatriação a gestão intercultural é instituída, a qual possui maior volume de estudos e pesquisas, mas a vinda de trabalhadores migrantes voltados às atividades operacionais demanda novos olhares e novos métodos de gestão, principalmente em um contexto em que os deslocamentos humanos estão em constante movimento.

Partiu-se do pressuposto de que, o domínio do conhecimento gerencial e técnico são requisitos primordiais diante das demandas do ambiente intercultural. A habilidade nas relações interpessoais seria um diferencial nas formações de gestores que estão interessados no aprimoramento do processo de gestão intercultural. A interpretação do "outro", cultura, diferença, identidade, são referências essenciais para o reconhecimento e adaptação do trabalhador migrante. Uma vez que, as condições culturais afetam a avalição, envolvendo o julgamento de alguém ou de algo como bom ou ruim. Usamos nossa própria cultura como um padrão de medida, julgando nossa própria cultura como normal e boa e tudo aquilo que é diferente como anormal e ruim (DAVEL; DUPUIS; CHANLAT, 2008). 
No contexto da categoria do reconhecimento do outro, infere-se que os resultados apontaram para a ausência de conhecimento dos gestores, singularmente, no que tange o aspecto cultural, inabilidade técnica, falta de empatia e dificuldade de interação. Para tanto, as proposições sugeridas indicam para a melhoria do preparo técnico e humano de gestores de equipes interculturais. Assim, é importante ao inserir trabalhadores de diferentes nacionalidades, a busca de conhecimento da língua, culturas, no sentido de propiciar a melhoria da integração do trabalhador, bem como facilitando o acompanhamento dos migrantes nas atividades laborais.

Em relação a categoria diferença cultural, o fator evidente é a limitação da inserção de trabalhadores estrangeiros, no grupo de trabalho em virtude do fator linguístico que dificulta sobremaneira o andamento das atividades laborais, a integração com os colegas de trabalho e demais hierarquias. Sugere-se que uma das maneiras de minimizar esses impasses de comunicação é oferecer aulas de português, viabilizando a aprendizagem da língua e a compreensão no ambiente organizacional, contudo os horários precisam ser compatíveis para o acesso dos trabalhadores migrantes.

A identidade revelou-se como fator relevante para a aproximação com o "outro", tal como para a troca de culturas entre brasileiros e haitianos, o que permite propor que seja realizado de maneira contínua tais interações, no sentido de compartilhamento de culturas, experiências profissionais, para a melhoria dos relacionamentos no ambiente de trabalho, impactando no alcance de metas, a partir desta interação. Verificou-se também, que os gestores entrevistados possuem significativa caminhada acadêmica, e para além disso, estão em contínuo aperfeiçoamento para gerir as diversas peculiaridades da gestão intercultural.

Contudo, é pertinente apontar os limites do estudo, tendo como limitação central a ausência do arcabouço teórico sobre gestão intercultural para equipes formadas de trabalhadores estrangeiros. As literaturas disponíveis discorrem sobre experiências de expatriados, geralmente de executivos que não é o caso do referido estudo. Esse limitador acabou por dificultar a comparação dos resultados com outros estudos sobre o tema envolvendo a categoria de profissionais advindos de outras culturas, especificamente, de trabalhadores em 
nível operacional. Apesar das limitações elencadas, e se tratando de um estudo inicial para a categoria de profissionais analisada, o trabalho explicita questões essenciais à compreensão de um tema de grande importância, ao qual seja a gestão intercultural, possibilitando a elaboração de novas hipóteses de pesquisa.

Sugere-se que estudos futuros sejam realizados contendo uma amostra mais ampliada em termos regionais, obtendo maior generalização dos resultados, bem como investigar a percepção dos trabalhadores provenientes de outros contextos culturais, como o Haiti, Venezuela.

Dentre as reflexões apresentadas, espera-se contribuir com o desenvolvimento de novos direcionamentos à gestão intercultural e aos profissionais que trabalham gerindo equipes interculturais, bem como para o meio científico, favorecendo a construção de outros estudos e na disseminação de novos conhecimentos sobre os temas aqui abordados.

\section{REFERÊNCIAS}

ALSINA, M. R. (In) comunicación. In: Congresso Internacional sobre El Diálogo Intercultural, Universidad de Murcia. Espanha, out. 2004. Anais. Universidad de Murcia, 2004.

ALVES, M.; GALEÃO-SILVA, L. 2004. A crítica da gestão da diversidade nas organizações. Revista de Administração de Empresas - RAE, v. 44, n. 3, p. 20-29, 2004.

ARANHA, D. F. Diversidade nas organizações: uma análise crítica sobre a teoria e a prática. São Paulo, 2018. 79f. Dissertação (Mestrado em Administração) - Escola de Administração, Fundação Getúlio Vargas, São Paulo: 2018.

BANISKI, G. M.; CIESLAK, R. (2018). A interculturalidade e sua influência na gestão do conhecimento: A experiência da Volvo do Brasil. Perspectivas em Gestão \& Conhecimento, v. 8, (N. Especial), p. 70-85, 2018.

BARBOSA, L.; VELOSO, L. A cultura do outro: Interculturalidade e dialogia nas empresas. In: Barbosa, L. Cultura e diferença nas organizações. São Paulo: Atlas, 2009.

BARDIN, L. Análise de conteúdo: Tradução Luís Antero Reto e Augusto Pinheiro. São Paulo: Edições 70, 2016.

BELK, R.; FISCHER, E.; KOZINETS, R. V. Qualitative consumer and Marketing research. London: Sage, 2013.

BERTUCCI, J. L. Metodologia básica para elaboração de trabalhos de conclusão de cursos (TCC): ênfase na elaboração de TCC de pós-graduação Lato Sensu. 1.ed. 3. reimp. São Paulo: Atlas, 2011. 
BUENO, J. M.; FREITAS, M. E. Representações sociais e ambiente intercultural nas organizações. In: MOURA, C. P., FERRARI, M. F. Comunicação, interculturalidade e organizações: faces e dimensões da contemporaneidade. Porto Alegre: Ed. PUCRS, 193-211, 2012.

BUENO, J. M.; FREITAS, M. E. Representações sociais no contexto intercultural: o cotidiano de três subsidiárias brasileiras. Cadernos EBAPE. BR, v. 16, n. 1, p. 101-118, 2018.

CANCLINI, N. G. A Globalização Imaginada. Tradução Sérgio Molina. São Paulo: Iluminuras, 2003.

CANCLINI, N. G. Diferentes, desiguais e desconectados: mapas da interculturalidade. Rio de Janeiro: Ed. UFRJ, 2005.

CARVALHO, J. I. S. Reflexões acerca do processo de imigração haitiana para a cidade de Cascavel - PR. In: XIV Semana Acadêmica de História. Diversidade, Ensino e Políticas públicas no século XXI. Marechal Cândido Rondon, 2017.

CHEVRIER, S. Le management des équipes interculturelles. Paris: PUF, 2000.

COX, JR. T. The multicultural Organization. Academy of Management Executive, v. 5, n. 2, p. 34-47, 1994.

CRAIDE, A. Intramobilidade e interculturalidade intranacional: desafios contemporâneos para profissionais e organizações. Salvador, 2001. 406 f. Dissertação (Mestrado em Administração). Escola de Administração. Universidade Federal da Bahia - UFBA. Salvador: 2011.

CRAIDE, A.; SILVA, F. A. A mobilidade e a gestão intercultural nas organizações. Revista Pensamento Contemporâneo em Administração, v. 6, n. 1, p. 105-123, 2012.

DAVEL, E.; DUPUIS, J. P.; CHANLAT, J. F. Gestion em Contexte Interculturel: approches, problématiques, pratiques et plongées. Québec: Pulaval, 2008.

FREITAS, M. E. A mobilidade como novo capital simbólico nas organizações ou sejamos nômades? Organização \& Sociedade, v. 16, n, 49, p. 247-264, 2009.

FREITAS, M. E. O Imperativo Intercultural na Vida e na Gestão Contemporânea. Organizações e Sociedade, v. 15, n. 45, p. 79-89, 2008.

FREITAS, M. E. Como Vivem os Executivos Expatriados e suas Famílias? Relatório de Pesquisa № 07/2000 NPP/EAESP/FGV, 2000.

DIAS, R. Cultura organizacional: Construção, consolidação e mudanças. São Paulo: Atlas, 2011.

FLEURY, M. T. L. Gerenciando a Diversidade Cultural: Experiência de Empresas Brasileiras. Revista de Administração de Empresas - RAE, v. 40, n. 3, p. 18-25, 2000.

FRANCO, M. L. P. B. Analise de conteúdo. 3. ed. Brasília: Liber Livro Editora, 2008.

FRIEDMAN, V. J.; ANTAL, A. B. Negotiating Reality: a theory of action approach to intercultural competence. London: Sage Publications, v. 36, n. 1, p. 69-86, 2005.

GALVIN, T. "Re-Evaluating Diversity": Reviving critical discourse in diversity research in organization studies. Academy of Management Proceedings, v.1, p. 1-6, 2006.

GEERTZ, C. A interpretação das culturas. Rio de Janeiro: LTC - Livros Técnicos e Científicos Editora S.A, 1989. 
GONDIM, S. M. G.; FISCHER, T. O discurso, a análise de discurso e a metodologia do discurso do sujeito coletivo na gestão intercultural. Cadernos gestão social, v. 2, n. 1, p. 9-26, 2009.

GUITEL, V. Intercultural or Cross Cultural Management? The evolution of the research field and the issue concerning the definition and the development of an intercultural competency for expatriates and international managers. Brussels: EIASM Workshop, 2004.

HAJRO, A.; GIBSON, C. B.; PUDELKO, M. Knowledge exchange processes in multicultural teams: Linking organizational diversity climates to teams' effectiveness. Academy of Management Journal, v. 60, n. 1, Advance online publication, 2015.

HOUSE, R.; HANGES, P.; JAVIDAN, M.; DORFMAN, P.; GUPTA, V. Culture, leadership, and organizations: The GLOBE study of 62 societies. Thousand Oaks: Sage, 2004.

IRIGARAY, H. A. D. R.; SARAIVA, L. A. S. Políticas de diversidade nas organizações: uma questão de discurso? Revista de Administração de Empresas, v. 49, n. 3, p. 337-348, 2009.

LLOYD, C. Thinking about the local and the local in the algerian context. Oxford Development Studies, v. 30, n. 2, p. 151-163, 2002.

MACHADO, H. V.; HERNANDES, C. A. Alteridade, Expansão e trabalho: implicações para a gestão internacional. In: XXVII Encontro Anual da ANPAD. Atibaia: Anais EnANPAD, 2003.

MATVEE, A. V.; NELSON, P. E. Cross cultural communication competence and multicultural team performance: Perceptions of American and Russian managers. International Journal of Cross Cultural Management, v. 4, n. 2, p. 253-270, 2004.

MENDES, R. H. Diversidade humana nas organizações: entre a teoria acadêmica e a prática empresarial. São Paulo, 2005. 106 f. Dissertação (Mestrado em Administração). Escola de Administração, Fundação Getúlio Vargas, São Paulo: 2005.

MINAYO, M.C.S. Pesquisa Social: teoria, método e criatividade. 29 ed. Petrópolis, RJ: Vozes, 2010.

NASI, L. Ativismo e a ativista na internet: reflexões sobre motivações para lutas sociais no marco da multiterritorialidade e do transculturalismo. In: MOURA, C.P.; FERRARI, M.A. Comunicação, interculturalidade e organizações: faces e dimensões da contemporaneidade. Porto Alegre: EDIPUCRS, 2015.

NKOMO, S.; COX, T. Diversidade e identidade nas organizações. In: CLEGG, S.; HARDY, C.; NORD, W. W. (Org.). In: Handbook de Estudos Organizacionais. São Paulo: Atlas, 1994.

PAULA, A. C. B.; SAMPAIO, G. H. Comunicação intercultural e os desafios do profissional em Secretariado Executivo em organizações multinacionais. Revista de Gestão e Secretariado, v. 9, n. 2, p. 72-95, 2018.

PEREIRA, J. B. C.; HANASHIRO, D. M. Ser ou não ser favorável às práticas de diversidade? eis a questão. Revista de administração contemporânea, v. 14, n. 4, p. 670-683, 2010.

PIRES, S. S. Gestão intercultural e cultura organizacional: o caso do Volkswagen Bank em Portugal. 2013, 151 f. Dissertação (Mestrado em Línguas Estrangeiras Aplicadas). Faculdade de Ciências Humanas. Universidade Católica Portuguesa, Portugal: 2013. 
RAMBO, R. A.; DIEHL, L. Diversidade cultural e seus impactos na prática profissional. Revista Estudo \& Debate, v. 22, n. 1, p. 97-115, 2015.

RODRIGUES, G. K. M. Culturas regionais no Brasil: um estudo sobre as percepções mútuas de gaúchos e baianos no ambiente de trabalho. 2012, 175f. Dissertação (Mestrado em Administração). Programa de Pós-Graduação em Administração, Universidade Federal da Bahia, Salvador: 2012.

RUAS, R.; ANTONELLO, C. S.; BOFF, L. H. Aprendizagem organizacional e competências. Porto Alegre: Bookman, 2005.

SAMPIERI, R. H.; COLLADO, C.F.; LUCIO, M. P.B. Metodologia da Pesquisa. 5. Ed. Porto Alegre: Penso, 2013.

SCHEIN, E. Organizational Culture and Leadership. San Francisco: Jossey-Bass, 1992.

SCHUERKENS, U. The sociological and anthropological study of globalization and localization. In: Global forces and local life-worlds: social informations. London: Sage, 14-26, 2004.

THOMAS JR, R. A diversidade e as organizações do futuro. In: A organização do futuro: como preparar hoje as empresas de amanhã. Editores Frances Hesselbein, Marshall Goldsmith, Richard Beckhard. 5. ed. São Paulo: Futura, p. 353-364, 2003.

TRIVINÕS, A. N. Introdução à pesquisa em Ciências Sociais: a pesquisa qualitativa em educação. São Paulo: Atlas, 2008.

VEBER, C.; LENGLER, L.; OLIVEIRA, J. M. O.; ESTIVALETE, V. F. B.; KNEIPP, J. M. A percepção dos gestores sobre as dimensões da sustentabilidade. Revista Sociais e Humanas, v. 29, n. 3, 2016.

VIEIRA, A. M.; RIVERA, D. P. B. A Hermenêutica no Campo Organizacional: duas possibilidades interpretativistas de pesquisa. Revista Brasileira de Gestão de Negócios, v. 14, n. 44, p. 261-273, 2012.

WAGNER, L. "Eu” e o “outro": executivos expatriados e itinerantes vivenciando uma nova realidade cultural no âmbito profissional e pessoal. Porto Alegre, 2009. 149f. Dissertação (Mestrado em Administração) - Pós-Graduação em Administração, Universidade Federal do Rio Grande do Sul, Porto Alegre: 2009.

WARNIER, J. P. A mundialização da cultura. Bauru: Edusc, 2000.

Recebido em: 23-03-2021

Aprovado em: 3-12-2021

Avaliado pelo sistema double blind review.

Disponível em http://mjs.metodista.br/index.php/roc 